\title{
Preliminary findings from the Mid-Atlantic Regional Assessment
}

\author{
Ann Fisher* \\ Department of Agricultural Economics and Rural Sociology, The Pennsylvania State University, University Park, \\ Pennsylvania 16802, USA
}

\begin{abstract}
This paper summarizes (1) the major positive and negative climate change impacts likely in the Mid-Atlantic Region (MAR), (2) options to make the MAR more resilient to climate change, and (3) priorities for improving such regional assessments. Major findings include: (1) the MAR economy is likely to be reasonably resilient to a somewhat warmer, wetter climate, although there could be substantial impacts on the region's ecosystems and some people will gain while others lose because of climate change; and (2) many cost-effective actions could be taken now to protect and enhance the quality of life in the MAR that would have side benefits of reducing vulnerability to climate variability and change.
\end{abstract}

KEY WORDS: Climate change impacts · Regional assessment · Assessment results

\section{INTRODUCTION}

As part of the first US National Assessment of potential impacts from climate variability and change, ${ }^{1}$ an interdisciplinary team at The Pennsylvania State University has been conducting an initial Mid-Atlantic Regional Assessment (M ARA). The M id-Atlantic Region (MAR) encompasses all or parts of 8 states and the District of Columbia (Fisher et al. 2000, in this issue, Fig. 3). Other articles in this Special describe the assessment process and sector-by-sector findings for the MAR. ${ }^{2}$ This paper synthesizes the findings from the articles in this Special (and other documents as noted) in order to identify which impacts might be most important for the MAR, accounting for the degree of

\footnotetext{
*E-mail: fisherann@psu.edu

${ }^{1}$ Researchers often define climate variation as natural variation in climate, and climate change as those variations and trends in climate attributable to human activity. For the purpose of assessing regional impacts, whether the cause of an impact is natural or anthropogenic is less important than whether it has to do with long-term trends or shorter patterns of variation. Thus the more intuitive definitions have been used for the MARA: climate variability refers to day-today, year-to-year, and decade-to-decade patterns of weather and climate; climate change refers to longer trends, usually measured by temperature and precipitation
}

uncertainty related to each category of impacts. It also identifies actions that could be taken to reduce the region's vulnerability, and summarizes priorities for data and research needed for improving efforts such as the MARA.

Any one assessment is unlikely to capture the richness of the framework shown in Fig. 1 (also appears as Fig. 4 in Fisher et al. 2000). A less daunting starting point for choosing specific assessment topics is to consider the pathways through which climate change can affect socioeconomic systems, as illustrated by Fig. 2 (and consistent with Fig. 1). Fig. 2a shows linkages among people, ecosystems, and climate; Fig. $2 \mathrm{~b}$ shows linkages among the global climate, a region, and other regions (in the United States as well as other countries).

${ }^{2}$ Fisher et al. (2000) list 4 questions guiding the MARA: (1) What are the region's current environmental stresses and issues that provide context for impacts from climate change? (2) How could climate change and variability exacerbate or ameliorate these stresses, or create new ones? (3) What actions could increase the region's resiliency to climate variability, reducing negative impacts and taking advantage of opportunities created by climate change? and (4) What are the short-term and long-term priorities for new information and research to better answer questions (1) and (2) and to evaluate adaptation options? 


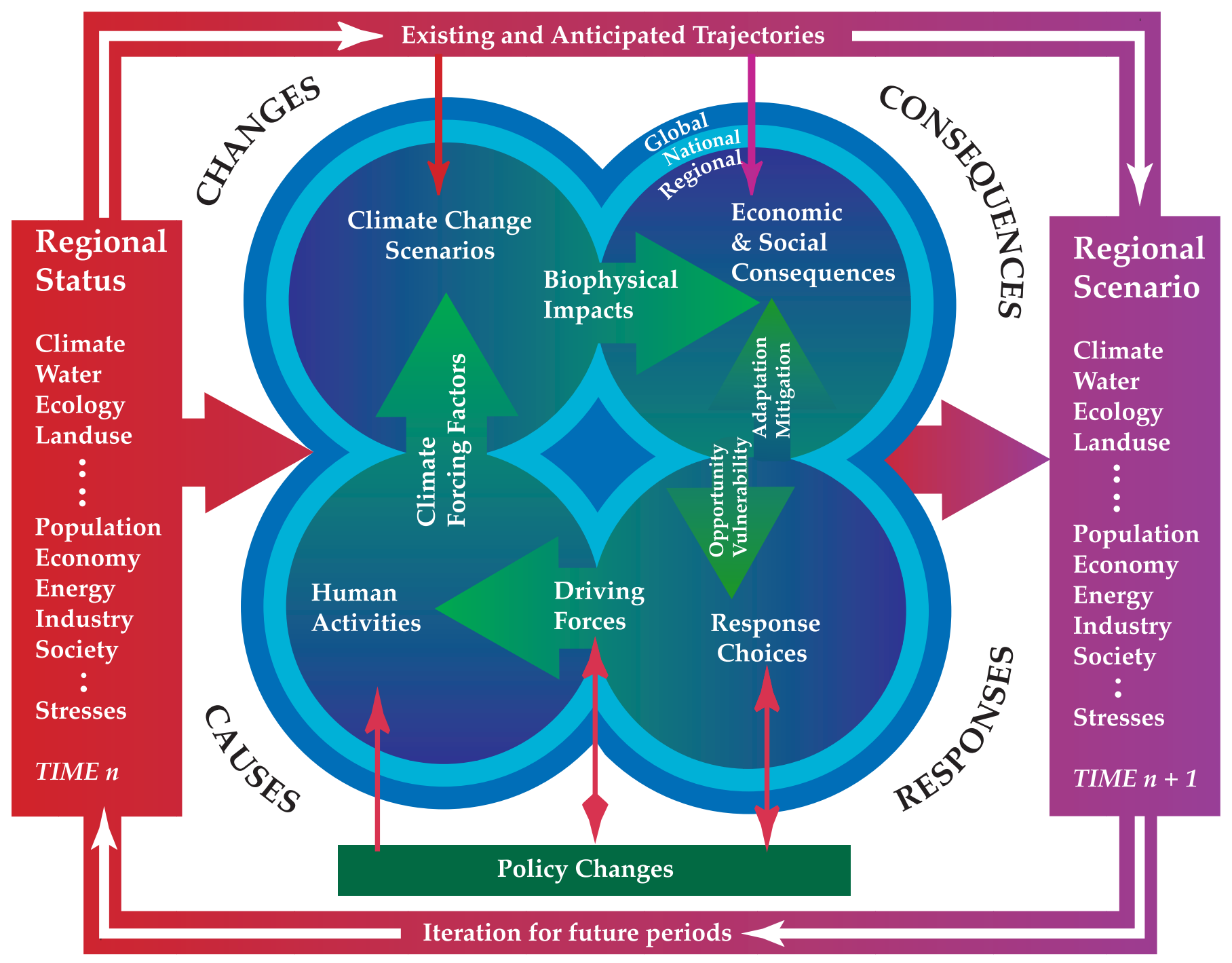

Fig. 1. Integrated regional assessment of global climate change

In the context of Fig. 2a, climate affects humans directly through the weather experienced (physically and psychologically) from day to day, or through the impacts of weather on daily living conditions, such as commuting times or recreational choices and experiences. Climate affects humans indirectly through its impacts on their economic, social and natural environment. The linkages between climate and human wellbeing in each of these systems is complex and dynamic. The potential domain is huge, so assessors must choose between direct and indirect effects, and within subcategories.

The distinction between market and nonmarket goods can help guide selection of assessment topics. ${ }^{3}$ The Intergovernmental Panel on Climate Change overview of potential market and nonmarket impacts of climate change indicates the state of the literature on estimating these impacts (Watson et al. 1996). For instance, agricultural products, forest products, water, and energy are market goods, because they are all bought and sold, at least in most countries. On the other hand, ecosystems, species, human health, and human life all are valuable yet there are no markets to assign prices to them.

\footnotetext{
${ }^{3} \mathrm{M}$ arket goods and services are those sold by an economic actor (a company, institution, household, or individual) to another economic actor, with payment being in cash, in kind (barter transactions), or both. Nonmarket goods are those that are not traded, and in which property rights are not well defined
} 


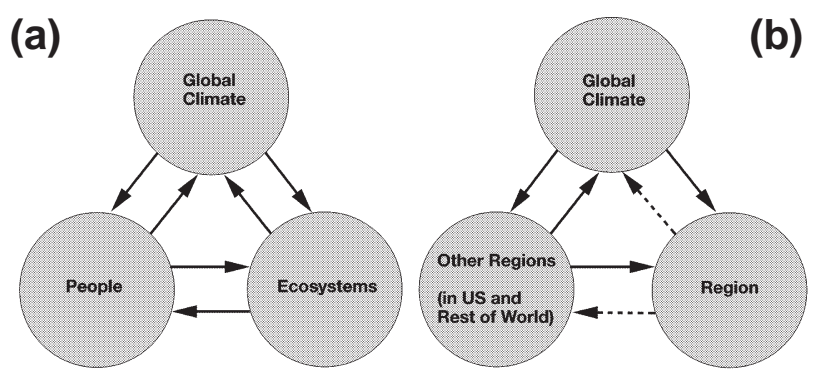

Fig. 2. (a) Climate-people-ecosystem interactions. (b) Climateregional interactions

The above considerations and input from stakeholders ( $\mathrm{O}^{\prime}$ Connor et al. 2000, in this issue) helped to identify the following criteria for choosing a set of impact categories and the depth to which each would be examined: (1) the importance of the impact category to the region's economic, social and environmental wellbeing; (2) expected sensitivity of the impact category to climate variability and change; and (3) the feasibility of performing a credible assessment of each impact category, given the available time and resources. These criteria led to assessment of MAR impacts on agriculture, forests, freshwater quantity and quality, coastal zones, ecosystems, and human health.

An initial step was to describe the region's present land forms, natural resources, demographics, economy and climate (Polsky et al. 2000, in this issue, Rose et al. 2000, in this issue). Because the region's society and economy will evolve regardless of whether climate change occurs, the second step envisions that evolution, with particular attention to components that are sensitive to climate. The third step assesses how the region's climate might change over the next century. The fourth step builds on the first 3, to assess the incremental regional impacts from climate change. As in Figs. $1 \& 2$, this step accounts for responses by people and their institutions, as well as ecosystems, to take advantage of new opportunities or to reduce damage caused by climate change. Because of the substantial uncertainties in envisioning the future and how people will adapt to it, the MARA team designed scenarios

\footnotetext{
${ }^{4}$ The MARA regional climate projections are based on global climate models from the Hadley Centre for Climate Prediction and Research in Great Britain and the Canadian Centre for Climate Modeling and Analysis (Polsky et al. 2000). Results from these models were supplemented by highresolution empirical and numerical downscaling models to extract information from the GENESIS global climate model (Crane et al. 1999). For some assessment components (e.g., McKenny-Easterling et al. 2000, in this issue), sensitivity analysis was conducted using other global climate models

${ }^{5}$ This presumes no major surprises (i.e., rapid, large non-linear responses) that would cause negative ecosystem impacts to dominate humans' overall well-being
}

expected to yield upper and lower bounds for both beneficial and detrimental impacts (Abler et al. 2000, in this issue). The fourth step also identifies anticipative actions that would reduce vulnerabilities or enhance opportunities for the future, plus information and research still needed to improve decisions related to the regional impacts of climate variability and change.

\section{SUMMARY OF KEY FINDINGS}

Earlier papers in this Special demonstrate many uncertainties in projecting (1) how the population, economy and environment of the MAR will evolve (especially Polsky et al. 2000, Rose et al. 2000, Rogers $\&$ M cCarty 2000, in this issue), (2) how the region's climate will change (Polsky et al. 2000), and (3) how changes in the region's climate will affect its population, economy and environment (entire Special). The uncertainties are compounded by the fact that different people, organizations, species and ecosystems have differing capabilities for adapting to the additional opportunities or stresses accompanying climate change. The findings are based on the convergence of climate model projections that the MAR overall will be somewhat warmer and somewhat wetter, with potentially more variability in the region's climate in the next 30 to $100 \mathrm{yr}$; this implicitly presumes that the causes of global climate change will not abate. ${ }^{4}$ Despite uncertainties in the preliminary assessment results, the region's citizens and decision makers can use them to inform near-term decisions that affect the future of the MAR. Summarizing and synthesizing the findings also may be suggestive for deciding what to examine in other regions.

\subsection{Impacts/consequences from changes in climate and climate variability}

The M AR economy is robust because it is diversified, technologically advanced, and highly integrated with the rest of the United States and the world (Rose et al. 2000). Its economy has relatively little dependence on climate-sensitive economic sectors within the region. For example, agricultural production and forestry each account for only about $1 \%$ of the region's gross output. These features make the MAR economy resilient to current climate variability. Along with anticipated technological, institutional and behavioral adaptations, these features and the assessment results summarized below suggest that the MAR economy will be reasonably resilient to projected climate change and its impacts on the region's natural resources. ${ }^{5}$ 


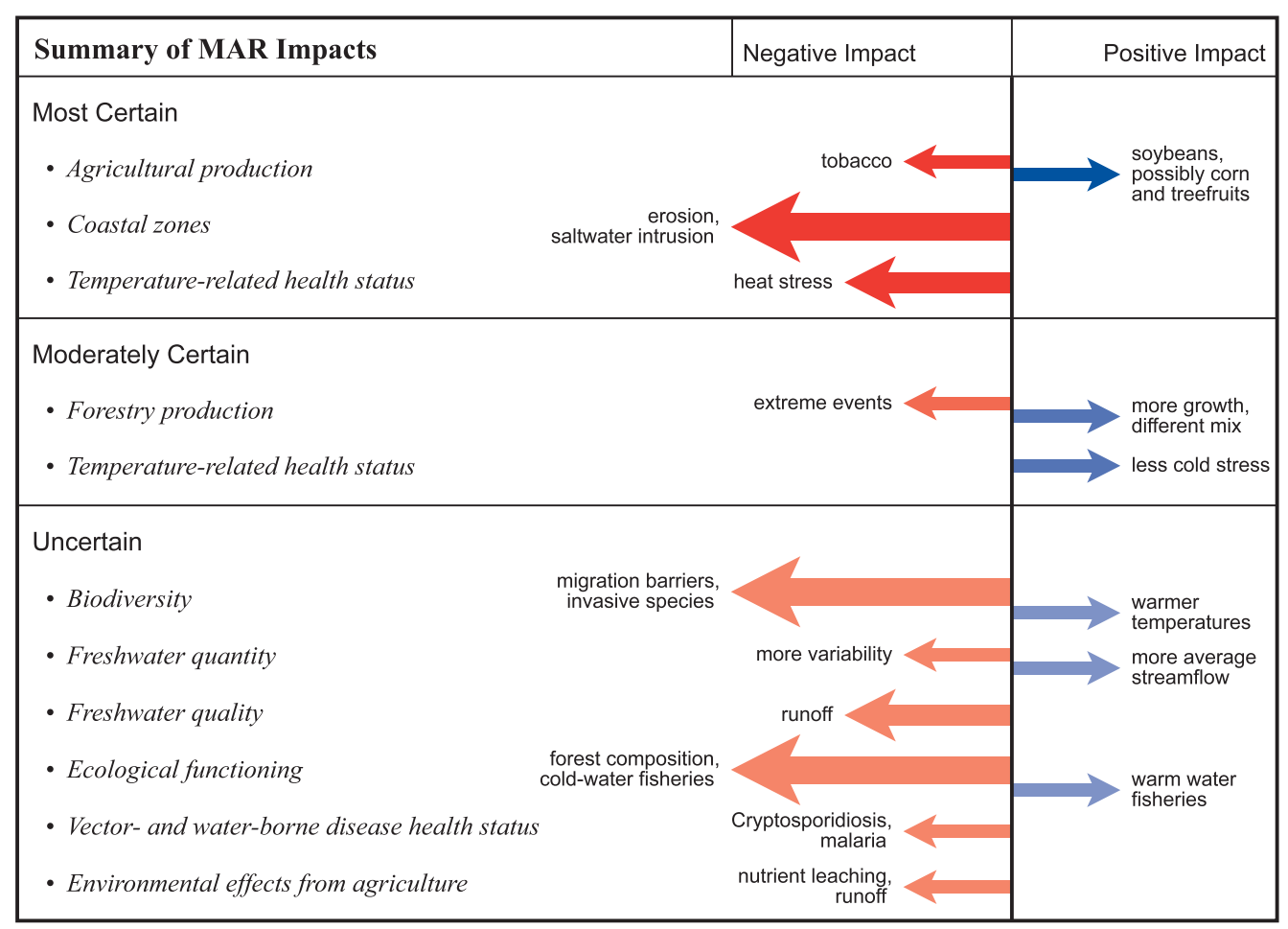

Fig. 3. Summary of MAR impacts

On the other hand, the MARA suggests that climate change poses diverse and potentially large risks to the region's ecosystems, which already show signs of stress (Rogers \& M cCarty 2000). Lingering effects from earlier degradation are compounded by continuing pressures on many of the region's ecological resources. Increased recognition of these pressures has come at a time of growing societal demand for ecological resource protection, both for its own sake and for recreational uses. These broad themes-economic resilience combined with ecological vulnerabilityare reinforced by the summary of results in the following subsections, and illustrated in Fig. 3.

\subsubsection{Agriculture}

Reflecting national trends, agriculture within the M AR has declined in importance while simultaneously adapting rapidly to changes in production and processing technology and to changing demands for different agricultural products. Abler \& Shortle (2000, in this issue; also see Abler et al. 1999) assessed potential impacts by 2030 for one scenario based on the status quo for the agricultural sector and for a second 'more environmentally friendly and smaller' (EFS) scenario. The EFS scenario is more likely, given the expected increases in regulation and higher values of land in other uses. Climate change is unlikely to have major effects on the region's agricultural production, because of farmers' ability to adapt, the fertilization and reduced transpiration effects of $\mathrm{CO}_{2}$, and the projected changes in regional temperature and precipitation. Despite uncertainties about how climate change will affect weeds and crop and livestock pests and diseases, there might be modest increases in the production of soybeans, and perhaps of corn and tree fruits. This is reflected by the small arrow in the top portion of Fig. 3. Climate change could have modest negative impacts on tobacco production, primarily from the indirect effects of increased competition from outside the MAR. This also is shown in the top part of Fig. 3. The region's other 2 major agricultural categories, dairy and poultry production, are not expected to be affected by climate change. The reasons are that the higher summer temperatures projected for the MAR are unlikely to be a major detriment to livestock production, and an increasing share of livestock production occurs under controlled (indoor) climate conditions.

The region's main environmental effects from agricultural production currently are nutrient and pesticide runoff, and erosion. If livestock production continues to be as important in the MAR as it is now (i.e., the status quo scenario), nutrient leaching and runoff could in- 
crease - particularly if there is a substantial increase in extreme weather events. The resulting water quality impacts could raise the risks of water-borne diseases and of ecological damage to freshwater and estuarine resources from eutrophication. Because of greater uncertainties about potential climate-induced environmental impacts from agricultural production, the corresponding arrow is in the bottom portion of Fig. 3.

\subsubsection{Forests}

Whether forests are managed for watershed protection, harvesting of saw timber, or maintenance of forest aesthetics, their managers report increased operating costs when extreme weather occurs (M cKenney-Easterling et al. 2000). These costs would be higher if extreme weather becomes more frequent or intense. Although projections of future patterns of extreme events are uncertain, there is more certainty that higher temperatures and changes in precipitation will affect tree growth and survival. Increased atmospheric concentrations of $\mathrm{CO}_{2}$ may fertilize trees and allow them to use water more efficiently. Using a statistical procedure developed by Iverson \& Prasad (1998) the MARA showed that climate change is likely to reduce the dominance of maple-beech-birch forests in the MAR and increase oak-hickory forests and, to a lesser extent, southern pine and mixed oak-pine forests. Overall primary forest productivity might increase, but shifts in forest types and their locations could diminish the competitiveness of the many small hardwood processors (e.g., for furniture and cabinetry) (McKenney-Easterling et al. 2000). Arrows in the middle portion of Fig. 3 reflect these potential impacts. Similar to the findings for agricultural production, forest changes are expected to be modest in size, but are somewhat more uncertain.

The relatively rapid shift in dominant forest types might foster invasive species and decrease biodiversity (and possibly ecosystem functioning) in the region's forests. Rapid shifts in forest types also might affect hydrology so that forests provide less filtering and moderation of stream flow. Relatively little is known about how the changes in forest types might affect recreation opportunities in forests. Along with conclusions from several of the following subsections, these findings contribute to the biodiversity, water quality and ecological functioning arrows in Fig. 3.

\subsubsection{Freshwater quantity and quality}

Rapid development in parts of the MAR that rely on groundwater wells, especially for residential use, has created stresses because of surface-water infiltration, or in the coastal zone, saltwater intrusion. Water systems also are sensitive to weather extremes. For example, at least $25 \%$ of surveyed water system managers reported difficulties at least once a year with each of the following: drought, floods, high and low air temperatures, electrical storms, snow, and wind (Fisher et al. 1999). Projections of stream flow (Najjar 1999) show a $24 \%$ increase by 2095 using the Hadley model, but a $4 \%$ decrease with the Canadian Climate Centre model. Despite these uncertainties, the potential for a wetter regional climate, punctuated by droughts, suggests higher water supply management costs to protect the quality of both surface- and groundwater sources and to provide more storage capacity ( $\mathrm{Neff}$ et al. 2000, in this issue). Increased storage capacity has the potential to buffer the region against additional flooding, if the extra precipitation tends to arrive in intense storms. However, as is true in many other areas, environmental concerns have made it increasingly difficult to build many types of water storage facilities. Smaller water systems and individual well owners have the disadvantage of not being able to spread storage or quality protection costs over large numbers of users. Fortunately, improved use of water markets could increase the efficiency of water use for both large and small systems. Uncertainties about future precipitation and stream flow lead to small water quantity arrows going in both directions in the bottom part of Fig. 3.

The effects of changed climate on the MAR hydrology are likely to stress ecosystems. Biological oxygen demand will be higher because the region's water bodies will be warmed somewhat by the higher average air temperatures. Runoff from thunderstorms and rapid snow melt will carry more contaminants and sediment to streams. Changes in the amount, timing, and quality of water might affect ecosystems from the headwaters throughout the drainage basins until they reach the region's estuaries and bays. In turn, this will affect recreation opportunities as well as the general quality of life. For example, habitat for warmwater fisheries will increase, while less habitat will be available for cold-water fisheries. Despite what might be viewed as offsetting effects, the average angler expresses willingness to pay modest amounts $\left(\$ 4 \mathrm{yr}^{-1}\right)$ to maintain the existing habitat distribution (Fisher et al. 1999). Because land use decisions will have long-lasting effects on the quantity and quality of runoff, future water resource vulnerabilities will be influenced by the interaction between land use decisions and climate change impacts. Although some of these impacts could be substantial, uncertainties lead to placing them in the bottom part of Fig. 3. 


\subsubsection{Coastal zones}

The dense population of the M AR coastal zone (38\% of the region's population in $15 \%$ of its area) puts people in harm's way from storm surges. Thus the benefit of longer coastal recreation seasons could be more than offset by storms. Storminess could increase in the MAR, but there is substantial uncertainty about its extent (Najjar et al. 2000, in this issue). Storm surges will be exacerbated by the effects of sea-level rise from climate change and from combined ongoing effects such as tectonics, post-glacial rebound, subsidence and subsurface compaction. The projected sea-level rise of $70 \mathrm{~cm}$ by 2095 would flood 22000 acres $(-8900 \mathrm{ha})$ in Delaware. Although only $1.6 \%$ of the state's land area, this amounts to $21 \%$ of its marsh area. The very diverse and productive ecosystems in salt marshes are vulnerable to sea-level rise, because sediments and organic matter are not deposited fast enough to allow them to keep up with sea-level rise and barriers often prevent inland migration. The costs of protecting valued infrastructure or natural areas could be quite high, and policies for strategic retreat from coastal areas are controversial.

Projecting impacts of climate change on MAR estuaries is complicated by uncertainties about future stream flows, which will affect both the quality and quantity of water reaching the estuaries. For instance, increased storminess could flush more nutrients, sediment and contaminants into the estuaries. There is more certainty that warmer temperatures will exacerbate already low summer oxygen levels in MAR estuaries because of increased oxygen demand and decreased oxygen solubility. Even by itself, warming will shift the location of some estuarine species northward. Although warmer winters might enhance habitat for the blue crab, which is commercially important in the Chesapeake and Delaware estuaries, warmer waters also sustain diseases that affect another commercially important species: oysters.

Coastal zones are both sensitive and vulnerable. Although a few potential positive impacts can be identified, the overall range of impacts in coastal zones contributes to the large negative arrow in the top part of Fig. 3, and to the large negative (but less certain) arrows for biodiversity and ecological functioning.

\subsubsection{Ecosystems}

Many ecosystem components are quite resilient, while others are very fragile. Changes in $\mathrm{CO}_{2}$ concentration, temperature, precipitation and sea level in the MAR will affect individual species differently, partly because ecosystems al ready are stressed in many M AR locations (e.g., forest fragmentation or cities and sea walls could hinder the migration of some species) and partly because of indirect effects (e.g., those that favor pathogens, parasites, predators, and competitors) (Rogers \& McCarty 2000). Development and wetland losses leave the MAR's rivers, streams, and near-shore areas vulnerable to damage from storms and increased input of sediments, nutrients and toxic substances, especially if precipitation increases. Aquatic and terrestrial populations of rare native species could decline because of climate-induced changes in habitat (such as a mismatch between when birds migrate and when food sources are available for them). Species that benefit (such as kudzu and gypsy moths) could crowd out others not directly affected by changes in climate variables, as well as those that suffer directly.

Although some desired species might become more abundant (e.g., because of increased habitat for warmwater recreational fisheries), the overall result is likely to be a reduction in biodiversity. Reduced biodiversity has uncertain implications for the ecosystem functioning that is crucial for ecosystem evolution as well as functions that people value, such as pollinating crops, moderating and purifying water flows, and providing diverse wildlife to observe. This subsection reinforces findings in other subsections that ecological impacts from changes in climate variability and climate could be quite large, but are uncertain. M ost of these impacts are judged to be undesirable. Thus the lower portion of Fig. 3 (reflecting substantial uncertainty) shows large negative impact arrows for biodiversity and ecological functioning.

\subsubsection{Human health}

M ortality directly related to heat, cold, storms, flooding, and lightning currently accounts for 0.13 deaths per 100000 population in the M AR (Benson et al. 2000, in this issue). The warmer, wetter, possibly stormier projections indicate that there could be increased morbidity and mortality from extreme events. The Benson et al. (2000) assessment suggests substantial percentage increases in heat-related mortality, but more uncertain, smaller decreases in cold-related mortality, as shown by the arrows in the upper 2 parts of Fig. 3 . While of concern, these increases still will account for a very small mortality rate. Even if climate change causes a large percentage increase in excess mortality (i.e., mortality above typical levels) from the weatherrelated causes listed above, their mortality rates would remain low.

The rates for the region's leading causes of death are 286 per 100000 for heart disease, 210 for cancer and 54 for strokes, which are similar to rates for the nation. 
Climate change could aggravate or contribute to the region's leading causes of death, but the more speculative indirect impacts from climate change could be more important. For instance, climate change could increase the region's risk from water-borne (e.g., cryptosporidiosis) and vector-borne (e.g., Lyme disease) diseases. The region's current and future health infrastructures are expected to be able to cope with these risks, albeit at increased costs from measures to protect the safety of food and water, control disease vectors, and provide health services. The elderly and those with limited access to health care could be disproportionately affected, particularly because of subregions with higher than average shares of the elderly and of those without health insurance. Thus a small negative arrow appears in the lower part of Fig. 3 for these health impacts.

\subsection{Win-win strategies identified for early action}

The MARA findings suggest 'win-win' actions that have substantial benefits even if climate stays the same, plus a bonus of making the region more resilient to climate change. Many of these win-win strategies will be cost-effective even in the absence of climate change but have not been high on society's agenda. It is desirable to consider these actions sooner rather than later because they make sense even in the face of substantial uncertainties in projecting global climate change and its impacts on the MAR. They are the following:

- Improve watershed management to reduce flood and drought damages and protect water quality (in streams and rivers, lakes and reservoirs, and ground water). For example, many communities do not have a watershed management plan even when the state requires one; implementation of existing plans tends to be uneven, too.

- Remove incentives for practices (e.g., that promote building or subsidize agriculture in areas vulnerable to erosion and flooding) that place people, investments and (especially coastal) ecosystems at greater risk to climate variability.

- Establish education and public information strategies that help the region's people identify how they can capitalize on benefits and ameliorate damages from climate change (such as the weather warning system that has been effective for reducing heat stress in Philadelphia).

The first 2 strategies would reduce risks from several causes-including climate change. They also would reduce ecosystem stresses; although less certain than the large threats to coastal zones, Fig. 3 indicates that threats to ecosystems could be quite large. More specific strategies are the following:
- Identify where coastal protection options such as beach nourishment, dikes or sea walls are cost-effective and where allowing coastal retreat is more costeffective; prepare strategies for dealing with losses (in wetlands, infrastructure) from sea-level rise.

- Improve water pricing to increase the efficiency of water use.

- Give higher priority to implementing government programs that indirectly reduce vulnerability to climate variability and change. Examples include the Safe Drinking Water Act regulations, coastal zone management plans, building codes, and land use planning.

- Foster forestry practices to encourage pine and oakhickory forests, including cutting to minimize wind and ice damage, and monitoring for potential increases in fire, insect pests and diseases that might be more prevalent under climate change conditions.

- Foster continued adaptation in agriculture, especially for precision agriculture and biotechnology (if concerns about unintended effects of biotechnology can be addressed).

- Monitor for the higher-risk climate-related disease vectors identified in the MAR.

\section{RESEARCH PRIORITIES AND INFORMATION NEEDS}

Priorities for maintaining and enhancing the mechanism for public involvement are outlined in $\mathrm{O}^{\prime}$ Connor et al. (2000). The list here focuses on gaps in the assessment and research required to fill those gaps. The most important information and research needs are the following:

- Improve projections for frequency, timing and intensity of mean and extreme weather (especially precipitation), at a regional level.

- Improve projections of how mean and extreme weather affect agriculture, forests, freshwater quantity and quality, coastal zones, ecosystems, and human health-including differences in the sensitivities and vulnerabilities of theses systems-and how adaptation would moderate negative impacts and enhance positive impacts.

- Improve models to evaluate the benefits and costs of alternative adaptation options, so that economic efficiency can be considered in management and policy decisions. For example, such decisions range from insurance coverage versus structural 'hardening' against extreme events to land use restrictions versus subsidized changes in land use.

- Improve methods for evaluating how proposed shifts in policy (e.g., health policy, land use policy, agricultural policy) might affect vulnerability to climate variability and change. 
More specific information needs include understanding the following:

- How changes in climate variables affect different types of ecosystems (with respect to ecosystem function, what fragile components might be replaced by invasive species or by indirect impacts because of changes such as in nutrient runoff, and how ecosystem changes affect disease vectors).

- How to assign values to climate-related changes in ecosystem components and processes.

- How biophysical impacts from climate change, especially related to ecosystem processes, affect people in different locations (e.g., rural vs urban, coastal vs inland) and with different characteristics (e.g., age, income, education) through impacts on their health, institutions, and other determinants of the quality of life.

- How best to provide information about climate variability and change (i.e., what types of information, what communication modes, what types of interaction strategies) so that diverse stakeholders can make more informed choices about actions that affect future opportunities and vulnerabilities.

- How temperature and precipitation interact, and implications for evapotranspiration, as well as direct $\mathrm{CO}_{2}$ impacts on evapotranspiration.

- How climate change would affect environmental impacts from development patterns, agriculture, and silviculture, including water quality, landscape amenities, and carbon sequestration.

- How temperature and humidity affect the immune system; how they interact with air pollution to affect conditions such as asthma.

- How climate change might affect weeds, insects, and diseases in crops, livestock, and forests, and how such adverse impacts might be controlled.

- How a warmer, wetter climate will affect the amount, timing, and quality of water available for human and ecosystem use.

- How adaptation in turn will feed back into the production of greenhouse gases.

\section{DISCUSSION}

The MARA finds that the regional economy will be resilient to climate change, but that climate change poses diverse and potentially large risks to the region's ecosystems. Fig. 3 emphasizes that the MAR can expect both positive and negative impacts from climate variability and change, causing some of the region's citizens and organizations to be better off while others will be worse off. This unevenness in who benefits and who suffers damage or costs is referred to as distributional impacts. These features-substantial overall economic resilience in concert with pressure on ecosystems and concern about distributional impactssummarize the region's basis for taking advantage of new opportunities created by climate change and for coping with its negative impacts.

Rather than a straightforward summation of simple measures, overall social well-being is a complex combination of economic, ecological and distributional considerations. The MARA findings provide insights for making better decisions in an uncertain world, with the goal of optimizing social well-being. A fundamental lesson from the MARA is that nonmarket goods deserve particular attention in assessing impacts from climate change. People having property rights in market goods stand to reap the rewards or suffer the consequences of direct and indirect effects of climate change on the value of their assets. This automatically gives them incentives to anticipate climate change and respond to its impacts. In contrast, while nonmarket goods are essential to human welfare and of great importance, the absence of markets for these goods means there is no automatic provision of incentives or mechanisms to reduce risks or exploit opportunities. Thus nonmarket goods tend to be neglected, relative to market goods. Moreover, many nonmarket goods are ecosystem services that are sensitive to the climate, but limited in their capacity to adapt to climate changes. The combination of missing markets and biophysical constraints on adaptation make ecosystems particularly vulnerable to climate change.

In the context of Fig. 2, an additional lesson for the choice of assessment topics is the implications of economic, demographic and ecological connections to other regions. For example, trade with other regions in forest and agricultural products can reduce the vulnerability of the region's consumers to climateinduced changes in the production of these commodities within their region. Conversely, both beneficial and adverse impacts of climate change in other regions can be transmitted through markets, human migration, and migration of wildlife and disease-carrying insects. Thus Fig. 2 can help set priorities within the more comprehensive framework shown in Fig. 1.

Acknowledgements. This work has been sponsored by the US Environmental Protection Agency, under Cooperative Agreement No. CR 826554 and the Pennsylvania State University. My special thanks to all members of the MARA team, especially to J. S. Shortle and R. J. Bord who provided comments on an early draft. I also appreciate the constructive comments from 3 anonymous reviewers and guest editor J. Scheraga. The views presented here are mine, and should not be attributed to the sponsors. 


\section{LITERATURE CITED}

Abler DG, Shortle J S (2000) Climate change and agriculture in the Mid-Atlantic Region. Clim Res 14:185-194

Abler DG, Shortle J S, Nizeyimana E, Corradini K (1999) Agriculture. In: Fisher A and 12 others (eds) Mid-Atlantic Regional Assessment (MARA) draft preliminary report on impacts from climate change. Prepared for USGCRP First National Assessment, sponsored by US Environmental Protection Agency, Cooperative Agreement CR 826554-01 (accessed: 1 October 1999); available at http://www.essc. psu.edu/mara/results/index/html

Abler DG, Shortle J S, Rose A, Oladosu G (2000) Characterizing regional economic impacts and responses to climate change. Global Planetary Change (in press)

Benson K, Kocagil P, Shortle J (2000) Climate change and health in the Mid-Atlantic Region. Clim Res 14:245-253

Crane RG, Yarnal B, Barron EJ, Hewitson B (2000) Scale interactions and regional climate: examples from the Susquehanna River basin. Human Ecol Risk Assess (in press)

Fisher A, N eff R, Barron EJ (2000) The Mid-Atlantic Regional Assessment: motivation and approach. Clim Res 14:153-159

Fisher A and 12 others (1999) Mid-Atlantic Regional Assessment (MARA) draft preliminary report on impacts from climate change. Prepared for USGCRP First National Assessment, sponsored by US Environmental Protection Agency, Cooperative Agreement No. CR 826554-01 (accessed: 1 October 1999): available at http://www.essc.psu.edu/ mara/results/index/html

Iverson LR, Prasad AM (1998) Predicting abundance of 80 tree species following climate change in the Eastern United States. Ecol M onogr 68(4):465-485

McKenney-Easterling M, DeWalle DR, Iverson LR, Prasad AM, Buda AR (2000) The potential impacts of climate change and variability on forests and forestry in the MidAtlantic Region. Clim Res 14:195-206

Najjar RG (1999) The water balance of the Susquehanna River Basin and its response to climate change. J Hydrol 219:7-19

Najjar RG and 15 others (2000) The potential impacts of climate change on the mid-Atlantic coastal region. Clim Res 14:219-233

N eff R, Chang H, Knight CG, Najjar RG, Yarnal B, Walker HA (2000) Impact of climate variation and change on MidAtlantic Region hydrology and water resources. Clim Res 14:207-218

O'Connor RE, Anderson PJ , Fisher A, Bord RJ (2000) Stakeholder involvement in climate research: bridging the gap between scientific research and the public. Clim Res 14: 255-260

Polsky C, Allard J, Currit N, Crane R, Yarnal B (2000) The Mid-Atlantic Region and its climate: past, present and future. Clim Res 14:161-173

Rogers CE, M CCarty J P (2000) Climate change and ecosystems of the Mid-Atlantic Region. Clim Res 14:235-244

Rose A, Cao Y, Oladosu G (2000) Simulating the economic impacts of climate change in the Mid-Atlantic Region. Clim Res 14:175-183

Watson RT, Zinyowera MC, Moss RH (eds) (1996) Climate change 1995: impacts, adaptations and mitigation of climate change. Cambridge University Press, Cambridge 